\title{
Practices using cassava leaves (Manihot esculenta Crantz) affected by mosaic in the Central African Republic
}

\section{Odilon Sylvain NGUEREPENDE ${ }^{1,2,3}$, Innocent ZINGA $^{2}$, Emmanuel KAMBA MEBOUROU ${ }^{2}$, Gorgon IgorTOUCKIA ${ }^{1}$,Serge Florent BOLEVANE OUANTINAM ${ }^{1}$, Silla SEMBELLA ${ }^{2}$ and Robert DJOUENKEU ${ }^{3}$}

\author{
${ }^{1}$ Higher Institute of Rural Development (ISDR) Of M'baiki University of Bangui \\ Central African Republic (CAR)
}

${ }^{2}$ Laboratory of Biological and Agronomic Sciences for Development (LASBAD), University of Bangui, Central African Republic (CAR).

${ }^{3}$ National School of Agro-industrial Sciences, Department of Food and Nutrition Sciences (SAN), University of Ngaounderé (Cameroon)

\begin{abstract}
In the Central African Republic (CAR), cassava is the staple food and the leaves are eaten. Mosaic virus infection could improve the organoleptic quality of the leaves and could also be a source of toxicity. The object was to study the level of food preferences of cassava leaves infected with mosaic virus and the level of their therapeutic uses. A survey was carried out in urban (Bangui) and rural (Lobaye and OmbellaM'poko) environments to assess the uses of cassava leaves infected by the mosaic. The results of this study show that the frequency of consumption in households varies from 1 to 4 times per week. The incidence of choosing infected leaves ranges from $76.7 \%$ to $93.3 \%$ in urban areas and $70 \%$ of the same respondents said cassava leaves with mosaic symptoms tasted excellent. This incidence was 30 to $40 \%$ in rural areas.On the other hand, $60 \%$ of respondents from rural areas claimed to have used cassava leaves for the treatment of certain diseases against $10 \%$ in the urban area. These results show that the culinary preference of cassava leaves showing symptoms of the virus could promote the spread of the virus by multiplying infected cuttings or susceptible varieties. This would constitute an obstacle to strategies to control the spread of this cassava pathology in CAR.
\end{abstract}

Keywords:Consumer, traditional medicine, leaf, cassava, mosaic, Central African Republic

\section{Introduction}

Cassava (ManihotesculentaCrantz) is the leading food crop in the Central African Republic (CAR) with an annual production of 2.9 million tonnes of fresh tuber [1]. Cassava leaves are eaten in several producing countries [2] and particularly in the CAR.The leaves are particularly rich in proteins, carotenes, minerals $(\mathrm{K}, \mathrm{Ca}, \mathrm{Na}, \mathrm{I})$ and vitamins (B1, B2, and C) [2]. In the Central African Republic, cassava leaves are among the vegetables most consumed by the population. There are more than a dozen recipes in the country made from cassava leaves [3]. The leaves are particularly rich in proteins, carotenes, minerals $(\mathrm{K}, \mathrm{Ca}, \mathrm{Na}, \mathrm{I})$ and vitamins (B1, B2, and C) [2]. In the Central African Republic, cassava leaves are among the vegetables most consumed by the population. There are more than a dozen recipes in the country made from cassava leaves [3]

Cassava adapts easily to difficult climatic conditions and poor soils. But it remains vulnerable to viral diseases. The main constraint of cassava in the Central African Republic is the mosaic virus [4]. African cassava mosaic is a viral disease that manifests itself mainly on young leaves as a light green or yellowish variegation at the blade level which deforms swells and grows asymmetrically [5]. However, this viral disease does not seem to constitute a constraint for the food use of cassava 
leaves, as, in the markets, cassava leaves yellowed by the mosaic sit alongside healthy leaves and seem to benefit from a good value. Steps. Some studies have shown that the protein content varies from 14 to $35 \%$ in cassava leaves $[6,7,8,9] \mathrm{A}$ recent study showed that the protein contents of leaves with mosaic disease were $22.88 \%$ compared to $12.77 \%$ in healthy leaves [9]. It should be noted that the Central African population has a preference for cassava leaves affected by the mosaic because of their taste considered very pleasant, according to observations made. The high protein content in cassava leaves could be linked to the presence of the viral capsid in them, which could partly explain the improved taste of leaves with mosaic symptoms. The purpose of this study is to assess the level of food and therapeutic use of cassava leaves infected with mosaic virus.

\section{Material and Methods}

\subsection{Material}

To carry out this work, we made use of GPS survey sheets and cassava leaves sold in the market.

\subsection{Methods}

\subsubsection{Study site and choice of respondents}

This work was carried out in the Central African Republic, in urban areas (Bangui), the target people were consumers who came to buy cassava leaves in the markets, and in rural areas (OmbellaM'poko; and Lobaye). Buyers and producers were interviewed. The geographic coordinates of each site were collected using a GPS (longitude, altitude and height).

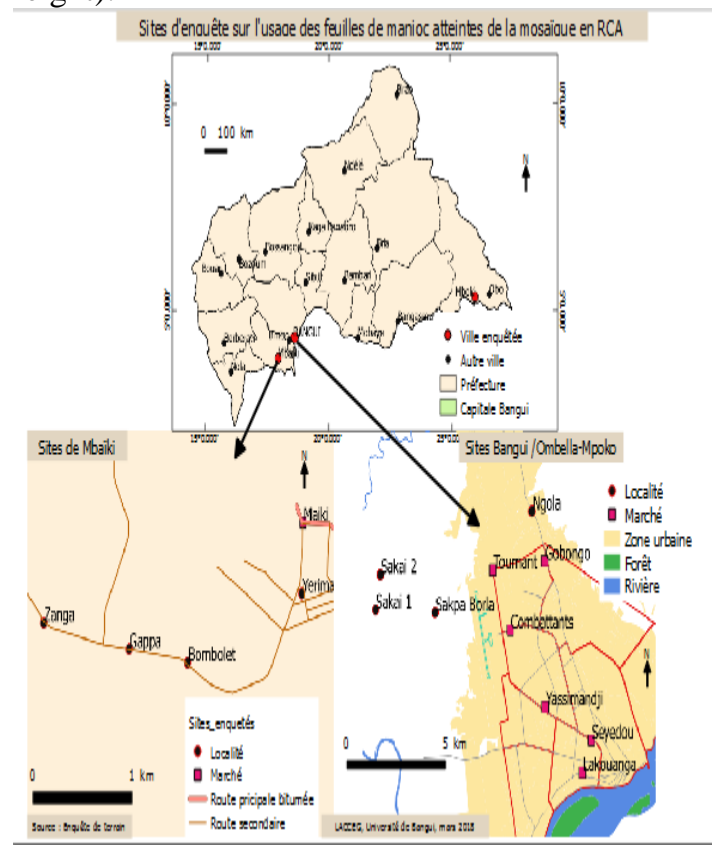

Source: LARSEN University of Bangui; 2019

Figure 1: Urban (Bangui) and rural (OmbellaM'poko and Lobaye) survey areas.

\subsubsection{Collection of data}

The surveys took place between April and November 2018 and 900 people were interviewed, using a structured questionnaire designed as part of this work. The questionnaires were of the closed and open type giving the possibility to the people questioned to express themselves.

The main questions answered by the questionnaire are:

-What is the frequency of consumption of cassava leaves in the household?

-What are the reasons for choosing the quality of cassava leaves consumed?

-Do you have any knowledge about the use of cassava leaves infected with mosaic virus in traditional medicine?

-What are the pathologies treated?

-Does the consumption of cassava leaves infected with mosaic disease have an impact on your health? -How does it manifest itself?

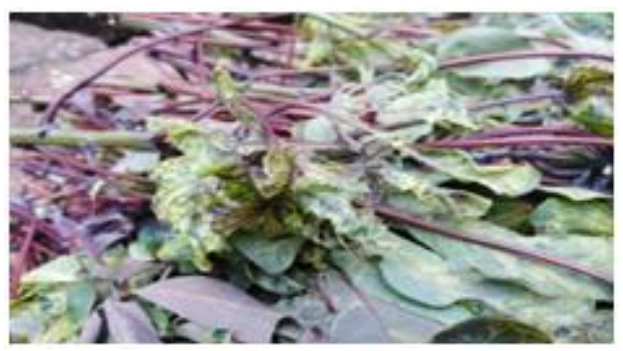

Figure 2a: Infected cassava leaves By the mosaic

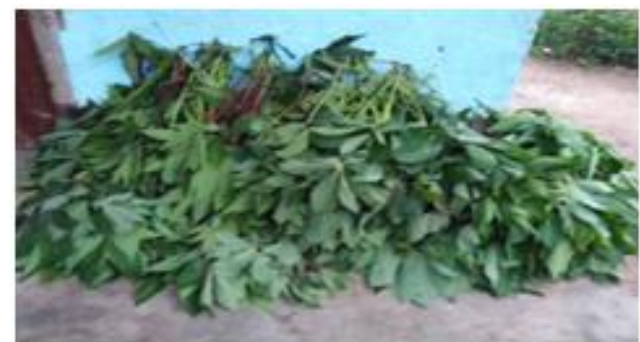

Figure 2b: Healthy cassava leaves.

Virus

\subsubsection{Statistical analysis of data}

The data were presented in a table; the multinomial logistic model was then used to analyze the data (frequency of consumption, choice of leaves, taste appreciation, impact of consumption of infected cassava leaves on health and knowledge on therapeutic use of cassava leaves). All tests were done using $\mathrm{R}$ software (version 3.2.3) and the probability level for observing a significant difference is 0.05 . 


\section{Results}

\subsubsection{Frequency of consumption of cassava} leaves in rural and urban areas

According to the results illustrated in (Figure 2). Cassava leaves are regularly consumed within a household in both rural and urban areas with a nonsignificant difference $(\mathrm{P}>0.05)$. The data recorded in rural and urban areas were grouped together in rural areas $\mathrm{P}<0.02$ and urban areas $\mathrm{p}<0.0001$. The frequency of consumption of cassava leaves in rural areas is statistically higher, at least four times a week. Note that in Bangui (urban) all the respondents claim to have consumed cassava leaves at least once a week

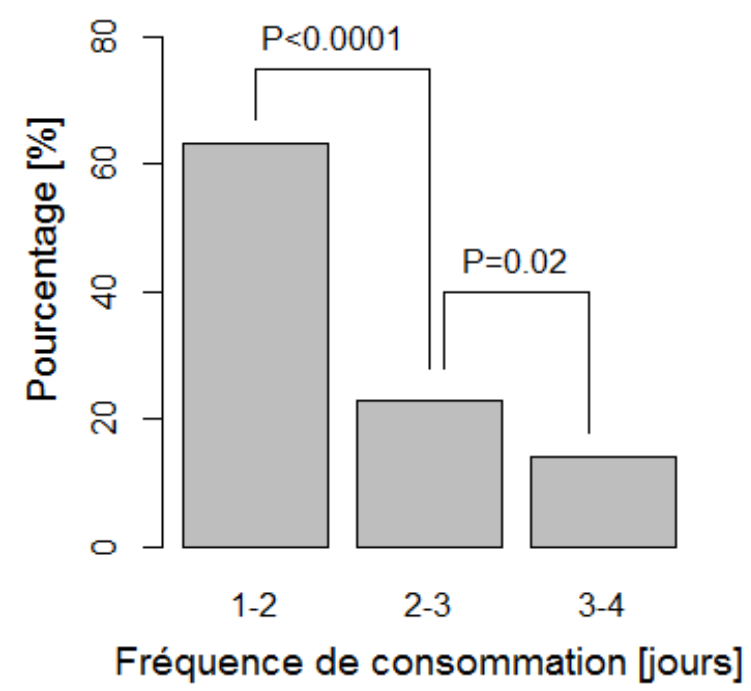

Figure 2: Frequency of consumption per week of cassava leaves within households in urban areas $\mathrm{p}$ $<0.0001$, and rural $\mathrm{P}<0.02$.

\subsubsection{Impact of consumption of cassava leaves on the health of respondents}

According to the results of the study, $80 \%$ of respondents in urban and rural areas (Figure 3) say that leaves affected by mosaic have no effect on their health. These results show that the consumption of infected leaves has a direct effect on the state of health of $17 \%$ of respondents, which manifests itself in the disruption of the menstrual cycle, digestive and gastric disorders. There is no statistical difference between the results for rural and urban areas $(\mathrm{P}>0.05)$. Leaves infected with mosaic virus would not pose enough health risks; according to surveys.
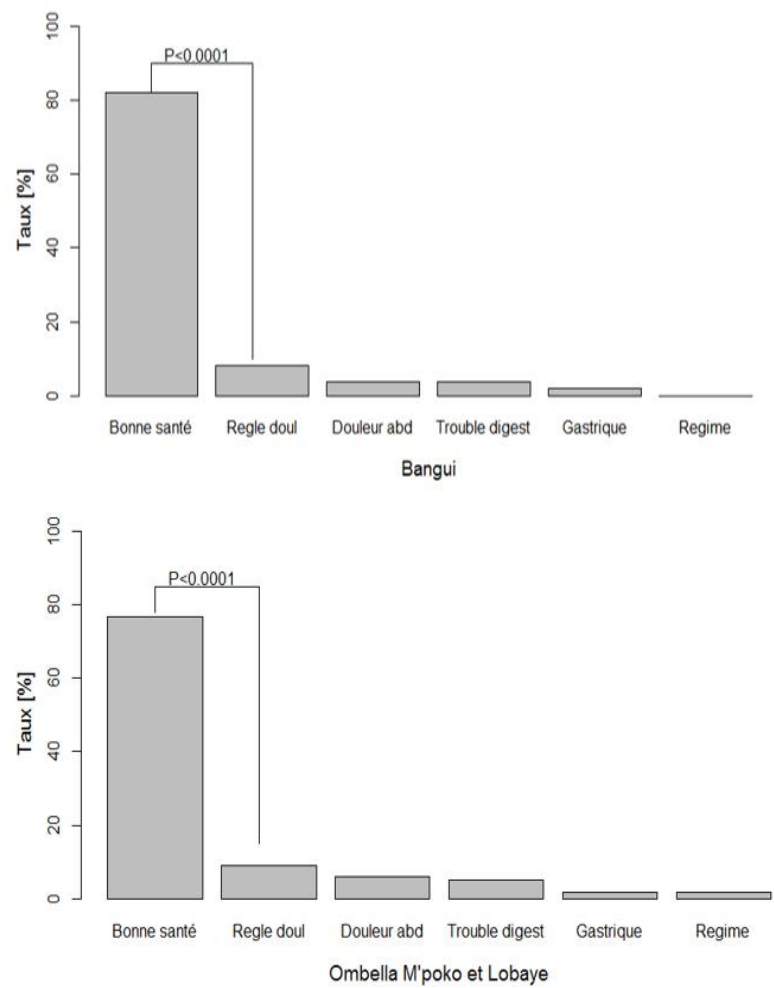

Figure 3: Impact of the consumption of leaves showing the symptom of mosaic in urban (Bangui) and rural (OmbellaM'poko and Lobaye) environments in the Central African Republic (Pain rule $=$ painful periods; Abd pain $=$ abdominal pain; Digestive disorder $=$ digestive disorders).

\subsubsection{Impact of choice of cassava leaves}

Figure $4 \mathrm{a}$ illustrates the level of choice of cassava leaves in urban markets. It should be noted that the incidence of the choice of leaves showing mosaic symptoms ranges from $76.7 \%$ to $93.3 \%$, with a significant difference compared to healthy leaves $(\mathrm{P}$ $<0.05)$. These results show that the quality of cassava leaves infected with mosaic virus meets consumer preferences.

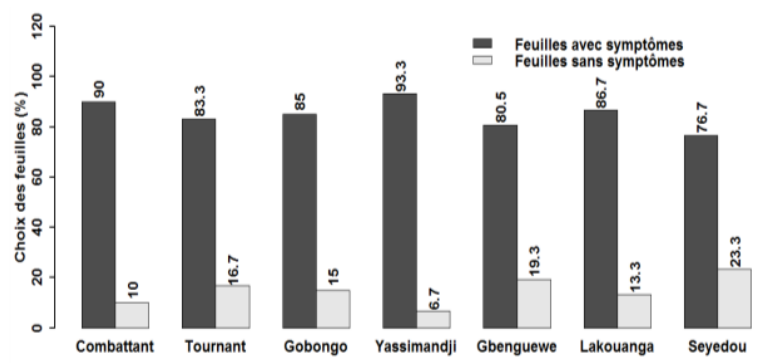

Figure 4a: Choice of cassava leaves in urban markets.

\subsubsection{Reason for choosing cassava leaves}

The results in Figure $4 \mathrm{~b}$ on the reasons for choosing cassava leaves show that $60 \%$ of respondents in urban and rural areas choose cassava leaves with mosaic symptoms because of their better taste. Since 
no difference was observed between the data from OmbellaM'poko and Lobaye, the data from these two prefectures were pooled. The results show that in these rural areas, the populations consider that the infected leaves are both very tasty and succulent as long as no difference was observed between these three criteria $(\mathrm{P}>0.05)$. Unlike respondents from Bangui, the healthy leaves were found to have a moderately good taste in rural areas. The most striking finding is that the healthy leaves were not rated as succulent. It also emerges that the combination of the two types of leaves is far from being described as better tasting in rural areas, compared to other criteria $(\mathrm{P}<0.0001)$

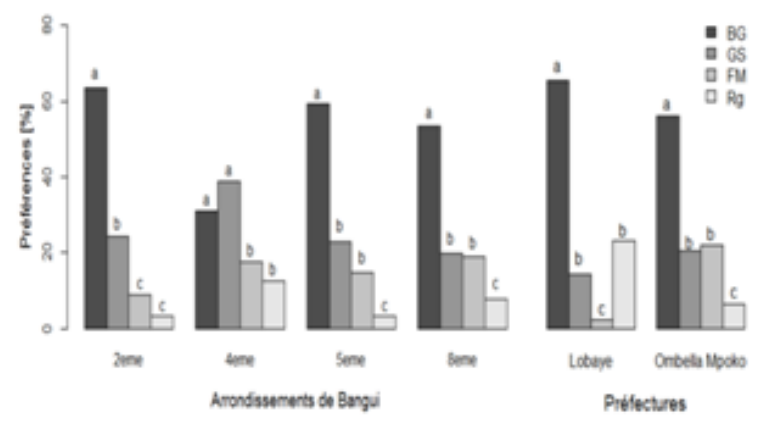

Figure 4b: Reason for choice of cassava leaves by consumers

\subsubsection{Use of infected cassava leaves in traditional medicine}

The results of (Figure 5) show that the cassava leaves affected by the mosaic are used for therapeutic purposes. The survey reveals that, $25.6 \%$ of respondents in urban areas use the infusion of the infected leaves to treat chickenpox, $6.4 \%$ to treat smallpox and $3.6 \%$ to treat anemia in children. . On the other hand in rural areas, $40 \%$ of respondents claim to have used cassava leaves infected with mosaic to treat chickenpox, $12 \%$ use to treat anemia, $10 \%$ of respondents use infected leaves to reduce pain. bee sting, $5 \%$ use its leaves to treat pneumonia in children

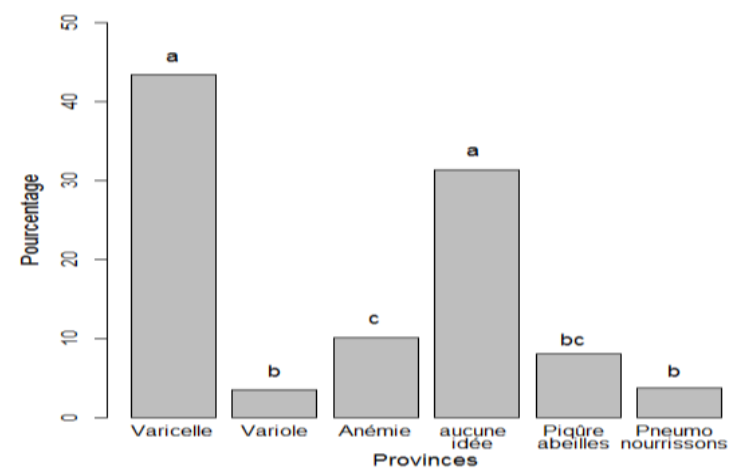

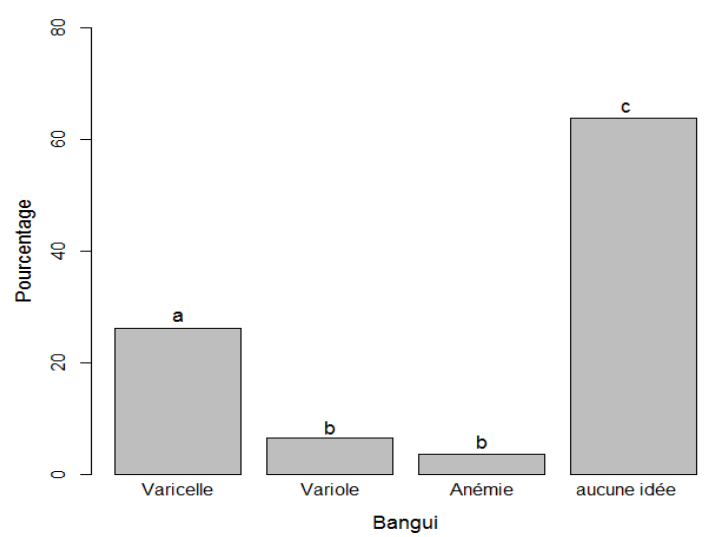

Figure 5: Knowledge of the medicinal use of cassava leaves in urban and rural settings. The percentages with different letters are statistically different according to a multinomial logistic model (the probability level is set at 0.05 )

\section{Discussion}

Cassava is one of the main crops fundamental for subsistence agriculture in CAR and feeds the majority of the population. The leaves are eaten as vegetables prepared according to the different types of recipes. Cassava leaves yellowed by the effects of the mosaic virus are appreciated in the different cassava leaf use practices in CAR. According to the results of surveys in urban and rural areas, it appears that about $60 \%$ of the people questioned prefer to consume the cassava leaves affected by the mosaic than the healthy leaves. These results support the hypothesis of [4], according to which the Central African population has a preference for cassava leaves with mosaic disease because of the taste considered pleasant. These results are in agreement with the work of [3], who suggest that culinary forms of cassava leaves infected with mosaic virus are considered to be of very good quality, which may be linked to the richness in viral protein.

Indeed, the criteria of preference for a better taste are the subject of an analysis in relation to the phytosanitary state of the cassava leaves (infected leaves, healthy leaves and a combination of healthy and infected leaves) and the organoleptic quality. According to the results of surveys carried out in urban and rural areas, cassava leaves affected by the mosaic are classified as very good taste, while healthy leaves are of average taste and have no impact on the health of the plants to the Consumers. The probability threshold is 0.05 ; there is therefore a significant difference, which shows that the phytosanitary aspect and other assessment criteria determine the quality of cassava leaves to be consumed in a household in rural and urban areas. These results verify the claims of [10], which state that cassava leaves are eaten as vegetables. It is for their magnificent taste that they are among the most consumed foods in West Africa. 
According to the results of studies carried out in urban and rural areas, it appears that cassava leaves are a common meal in households in the Central African Republic 60\% of respondents consume cassava leaves on average once or twice a week, while $20 \%$ of people questioned can eat at least 2 to 3 times in a week and that the number of people who can eat cassava leaves 3 to 4 times in a week is $10 \%$. These results agree with the hypothesis of [5] that cassava leaves are of greater nutritional value in CAR compared to the results of surveys carried out in urban areas. In rural areas, nearly $80 \%$ of respondents say that consuming cassava leaves affected by mosaic disease has no impact on their health. However, cassava leaves showing symptoms of mosaic disease have an effect on the health of $17 \%$ of those questioned. The probability that a consumer will have a health problem after consuming the leaves showing symptoms of mosaic disease is $\mathrm{P}<0.0001$.

This finding shows that cassava leaves infected with mosaic can be a source of minor contamination, the results of which of work by [2] stipulate that the consumption of cassava leaves can thus cause poisoning with symptoms such as headache, dizziness, diarrhea and vomiting. This also makes it possible to confirm the results of our work, because cassava leaves affected by mosaic are a prohibited food in certain people with a history of health or suffering from certain gastric pathologies, abdominal pain, painful periods and disorders digestive.

So we can say that the health problems could be related to the culinary aspect. The results of surveys on the therapeutic use of cassava leaves in urban and rural areas show that $25.6 \%$ use leaves infected with mosaic to treat chickenpox (viral disease), $6.4 \%$ of respondents use the leaves. infected in the case of smallpox (viral disease), while $3.6 \%$ use a decoction of these leaves in cases of anemia. Compared to the results of studies carried out in urban areas, on therapeutic use, we see that there is a significant difference between the results in rural areas. Cassava leaves infected with mosaic are used by $40 \%$ of respondents in rural areas in traditional medicine to treat chickenpox; and $12 \%$ of respondents use them in the case of anemia and less than $5 \%$ in the case of of the treatment of pneumonia in children. The results of this study confirm those of [11] on local knowledge and cassava production in CAR, that cassava leaves of varieties six months susceptible to mosaic, are used for therapeutic purposes to treat chickenpox or keteyangba (sango language), smallpox or kotayangba (sango language), hemorrhages, open wounds, snakebite, lice and quid, insect bite, wasps, scorpion, pneumonia in the child. These results correlate with previous studies carried out by [12], which show that certain plants contain metabolites to allow them to be nutrients, that is to say to nourish and heal both, in particular the leaves of the cassava which are rich in condensed tannins and protein. According to the results of studies carried out, cassava leaves infected with the mosaic virus could contain molecules that are active on certain pathologies, which an in-depth study will allow to isolate and characterize.

\section{Conclusion}

This work has made it possible to collect information on the use of cassava leaves infected by the mosaic in households in the Central African Republic. Cassava leaves are consumed by almost all of the Central African population and the survey carried out in urban and rural areas shows that consumers prefer cassava leaves affected by the mosaic because of the highly appreciated organoleptic quality and that they adapt to different forms of culinary preparation. Reinforcing common foods with mosaic-affected cassava leaves that are mostly high in protein and other nutrients can be a sustainable and cost-effective approach to tackling protein deficiency. The study reveals that cassava leaves infected with the mosaic virus are known to have therapeutic properties in the Central African Republic. The main diseases treated are: chickenpox, smallpox and anemia. Cassava leaves affected by the mosaic present several scientific interests that must be explored.

\section{Competing interests}

The authors declare that there is no conflict of interests regarding the publication of this paper.

\section{Acknowledgments}

The authors are grateful to the PRASAC (Regional Center for Applied Research in the Development of Agricultural Systems in Africa), in C.A.R, for providing the financial the necessary facilities and constant encouragement for the present study.

\section{References}

[1] FAOSTAT, 2017 .Data base. Food and Agriculture Organization of the United NationRomeItaly:htt://faostat，2017.fao.org / browse / Q / QC / E. consulted in 2017

[2] Joachim M .; 2016 Cassava all-in-one food study Institute of Agricultural Engineering University of Hohenhim, Germany 4 Pages. Site web : www.rural21.com consulted in 2017.

[3] Kosh-komba E., 2013. Farmer management, agro-morphological and genetic diversity of cassava (ManihotesculentaCrantz), cultivated in three agro-climatic zones, doctoral thesis, P 51-53.

[4] Zinga Innocent 2012 Epidémiologie de la mosaïque du manioc en République 
Centrafricaine, résistance variétale et assainissement par thermothérapie thèse de doctorat $\mathrm{P}$ 7-36.

[5] Ballot C; 2016 Integrated management of crop soil fertility (ManihotesculentaCrantz) in the Damara area in the Central African Republic Doctoral thesis, University of Lomé Faculty of Sciences P 17-24.

[6] Louembé D ;; 2003. Microbiological study of fermented cassava leaves scientific article 6 Pages

[7] Bede N,1980. Nutritional implication of Projects Giving High Priority to the production of staples of low nutritive Quality the casa for cassava food Nutrit.Bull, 2,1-10.

[8] Lambrechts A and al 1961. Food and Agricultural Survey in Rural Populations of Haut-Katanga.Briefs collection.Vol 11: 69. net

[9] OYOR J, 1990, Cassava in tropical Africa. A reference manual.Ibadan, Nigeria, ITTA.190 Pages.

[10]Zinga Innocent; 2016 Evaluation de la teneur en protéine et en chlorophylle dans les feuilles de cinq variétés locales du manioc infectées par mosaïque de manioc République net
[11] Bamada J, 2018 A plant and its virtues: Cassava leaves a natural remedy for our health. http://bamada.net, consulted in 2017

[12] Tebero J; 2018: Local knowledge and cassava production in the Central African Republic scientific article 17 Pages. http://www.credef-ub.org. consulted in 2019

[13] Marie Madeleine C; 2009. Study of the effect of a cassava-based diet on gastrointestinal parasitism and on the growth of lambs.Scientific article. 2 Pages

[14] Mallouhin N. et al, 2002. Study of the impact of the African cassava mosaic in the Central African Republic.CT / ICRA, 16 Pages.

[15] Udo and, John;. 2015. Effects of processing methods on the utilization of cassava (ManihotesculentaCrantz) leaf meal (CLM) by Africa cafish). Livestock Research for Rural Development, 27 (8). Online.

[16] Mallouhi N. and al, 2002. Summary note of cassava cultivation in the Central African Republic. ICRA, 16p.

[17]Dada Adigu O and al. 2010. Mineral and Nutrient Leaf Composition of Two Cassava (ManihotesculentaCrantz) Cultivars Defoliated at Varying. 